\title{
México y Chile: paradojas democráticas e injusticias distributivas
}

\author{
Carlos Alberto Díaz*
}

\begin{abstract}
Resumen
Las configuraciones distributivas del Estado, las herencias institucionales dictatoriales y/o autoritarias, la corrupción y la violencia, influyen en las dimensiones culturales de la democracia y la desigualdad en México y Chile. Estos factores han actuado históricamente como dilatadores de la desigualdad mediante redes políticas oscuras, que están presentes de distinta forma en el desarrollo de sus Estados y sus economías. Cuando los rasgos ilegales e informales de estos dilatadores son valorados positivamente, se alteran la solidaridad, la participación en asuntos públicos y la posibilidad de que las contradicciones de la desigualdad se hagan visibles en el espacio público.
\end{abstract}

Palabras clave: Dilatadores de la desigualdad - redes políticas oscuras - injusticia distributiva.

\begin{abstract}
State distributive configurations, dictatorial institutional legacies and/or authoritarian, corruption and violence, influence on the cultural dimensions of democracy and inequality in Mexico and Chile. These factors have historically acted as dilators inequality through dark political networks, which are present in different ways in the development of their countries and their economies. When illegal and informal features of these stents are valued positively, solidarity, participation in public affairs and the possibility that the contradictions of inequality become visible in public space are altered.
\end{abstract}

Keywords: Inequality dilators - dark political networks - distributive injustice.

* Doctor en Ciencias Políticas y Sociales, Universidad Nacional Autónoma de México. Becario posdoctoral, Consejo Nacional de Ciencia y Tecnología, México. Correo electrónico: carlosdgm2001 @yahoo.com.mx 


\section{INTRODUCCIÓN}

¿Qué procesos explican el devenir de la cultura democrática mexicana y las percepciones de la desigualdad de su sociedad?, ¿a qué responden los contrasentidos que detectamos?, ¿por qué dentro de la cultura democrática chilena ocurre mayor resistencia a la desigualdad que en México, pese a que la institucionalidad dictatorial no la favorece?, ¿qué clase de procesos influyen las dimensiones culturales de la democracia y la desigualdad, haciendo la diferencia entre ambas naciones?

Responder a estas incógnitas implica explorar el terreno de las ambigüedades, reconociendo, como lo expresa Maffesoli, "que la paradoja es la marca esencial de los momentos cruciales y de los cambios históricos". Y que "en América Latina tal parece que las paradojas han sido una constante en su historia" (2004: 6). Por eso, nuestras respuestas pretenden identificar los aspectos estructurales y culturales que envuelven las contradicciones de la democracia y la desigualdad, situándolos en su mutua y compleja relación.

En ese esfuerzo, analizaremos cómo la influencia de las configuraciones distributivas del Estado pesan en la cultura democrática y la cultura de la desigualdad de chilenos y mexicanos. En ambas influyen también otros aspectos estructurales como las herencias institucionales dictatoriales, la corrupción y la violencia, en los que nosotros vemos dilatadores de la desigualdad. Estos casi siempre van a funcionar mediante redes políticas oscuras, con un componente de permisividad que contrasta la realidad mexicana con la chilena, debido al modo tan distinto en que han logrado penetrar el desarrollo histórico de sus Estados y sus economías.

Dicha permisividad está relacionada con la adaptación social a la desigualdad y con la cultura democrática, pues contiene valoraciones que vuelven funcionales los rasgos ilegales e informales de los dilatadores, alterando la solidaridad, la participación en asuntos públicos e incluso la posibilidad de que las contradicciones de la desigualdad se hagan visibles en el espacio público. Estos argumentos están concebidos a manera de hipótesis y nos servirán para explorar las distancias de la cultura democrática y la cultura de la desigualdad entre ambos países.

\section{MEXICANOS Y CHILENOS: HORIZONTES DE LA CULTURA DEMOCRÁTICA Y LA CULTURA DE LA DESIGUALDAD}

Es posible observar dentro del período de las democratizaciones en México y en Chile, un aumento en las aspiraciones por mayor igualdad económica, articuladas con el incremento real de la desigualdad en los ingresos y con su percepción como un hecho injusto. Así por ejemplo, a la par del ensanchamiento que tuvo la proporción de quienes pensaban que los ingresos debían ser más igualitarios -y que en el intervalo 1989-1993 llegó a 16\% en Chile y a 13\% en México, alcanzando de 1999 a 2004 el 33\% y el 24\%, respectivamente (Encuesta Mundial de Valores, 2014)-, en esta última nación la desigualdad se eleva y se mantiene alta desde 1989 hasta el 2000 (Cortés, 2013: 12). Es decir, el coeficiente de Gini pasa de 0,483 a 0,493 (Cortés, 2013: 19), mientras que en Chile aumenta de 0,540 
a 0,569 (CASEN, 2014). Y aunque más adelante mejora la situación en ambos países y la participación de los ingresos del quintil más pobre crece y la de los ricos disminuye ${ }^{1}$, el $87 \%$ de los chilenos y el $76 \%$ de los mexicanos consideran injusta la distribución de los ingresos (Latinobarómetro, 2013: 78).

\section{GRÁFICO 1}

Aspiración igualitaria de ingresos

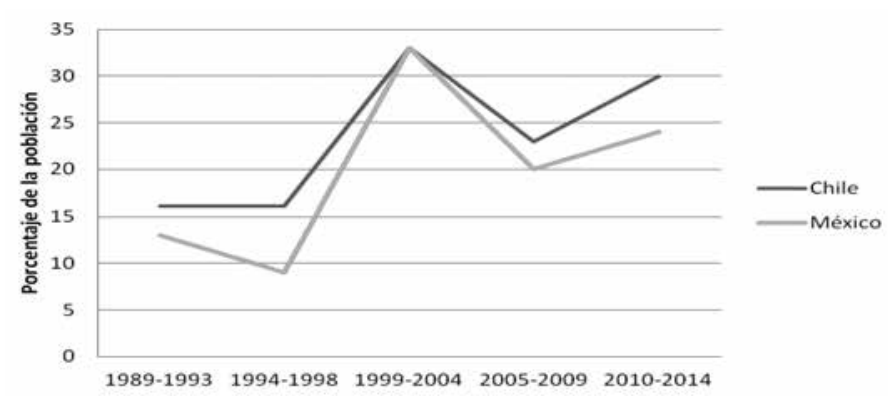

Fuente: Elaboración propia con base en la Encuesta Mundial de Valores (2014).

Paradójicamente, dicho escenario despliega tendencias muy marcadas que distinguen a los mexicanos de los chilenos, en las que por ejemplo aquellos apuestan considerablemente por las grandes diferencias de ingresos y por la competencia entre individuos ${ }^{2}$, en un claro contrasentido a la idea de igualdad, porque más que funcionar como incentivos para la movilidad social ascendente, son características de una cultura que termina legitimando y reforzando una amplia gama de brechas sociales.

El problema se complica cuando añadimos las opiniones ambiguas de los mexicanos acerca de la intervención del Estado para igualar los ingresos y su reticencia a solidarizarse con los más pobres mediante el sistema fiscal ${ }^{3}$; peor aún si observamos el apoyo decreciente que recibe la democracia, la baja satisfacción que les genera ${ }^{4}$ y los niveles precarios de

1 De 2008 a 2012 la participación de los ingresos del quintil más pobre en México pasó de 5,8\% a 6,6\% en 2012 y la de los más ricos disminuyó de 49\% a 46.2\%, mientras que en Chile la del quintil más pobre creció de $5,3 \%$ a $5,7 \%$ de 2008 a 2013, y la del más rico se redujo de 53,5\% a 52,1\% (CEPAL, 2014: 24). Según la Encuesta Suplementaria de Ingresos, para 2013 las familias más pobres de Chile aumentaron sus ingresos autónomos en $20 \%$ respecto de 2010 . Si a estos se suman los subsidios estatales, se estima que sus ingresos se incrementaron 39\% (El Mercurio, 10/12/2014).

2 En los períodos 1989-1993 y 1994-1998, 14\% de los mexicanos declara ser afín a que en la sociedad existan grandes diferencias de ingresos como incentivos, elevándose a 21\% de 1999 a 2004 y a 22\% de 2005 a 2009. De 1994 a 1998, el 24\% ve en la competencia un estímulo para que la gente trabaje duro, aumentando a $38 \%$ de 1999 a 2004 y a 49\% de 2005 a 2009 (Encuesta Mundial de Valores, 2014).

$320,1 \%$ de los mexicanos considera como característica esencial de la democracia que el Estado iguale los ingresos, frente al 20,9\% que piensa que no. Además, 25,4\% está en contra de que los impuestos de los ricos subsidien a los pobres (Encuesta Mundial de Valores, 2014).

4 En 2004, 69,8\% apoyaba la democracia, 69,2\% en 2006, 68,5\% en 2008, 66,8\% en 2010, 63,6\% en 2012 (Barómetro de las Américas, 2010: 42; 2013a: 86) y 37\% en 2013 (Latinobarómetro 2013: 19). De hecho, en 
participación política tanto formal como informal, que aparecen matizados por participaciones políticas de tipo societal ${ }^{5}$.

En oposición al paisaje mexicano, los chilenos son poco afines a las grandes diferencias de ingresos y a la competencia individual, vistas como vías que conducen a la igualdad ${ }^{6}$. Destaca también su proclividad hacia la intervención del Estado en materia distributiva, no solo porque trata de la igualación de ingresos, sino porque coincide con favorecer el uso de impuestos para subsidiar a los pobres ${ }^{7}$.

\section{GRÁFICO 2}

\section{Apoyo a las grandes diferencias de ingresos como incentivos}

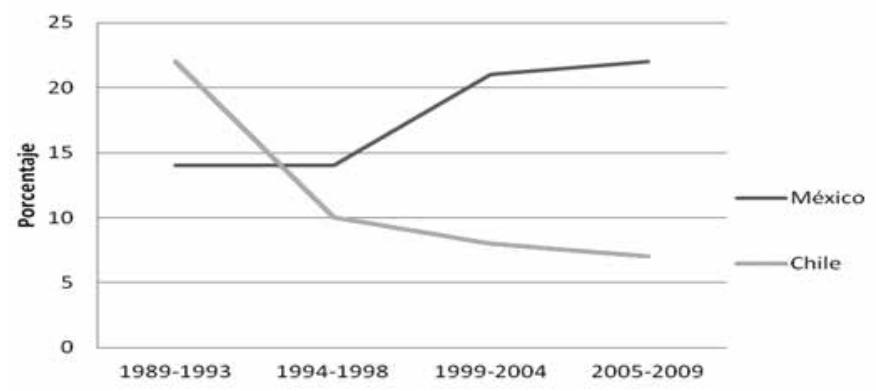

Fuente: Elaboración propia con base en la Encuesta Mundial de Valores (2014).

el período 1995-2013 México perdió doce puntos porcentuales de apoyo a la democracia (Latinobarómetro, 2013: 19), que no recupera pese a que en 2015 sube a 48\% (Latinobarómetro, 2015: 40). Por su parte, considerando una escala de 0 a 100, la satisfacción con la democracia disminuye de 50,4 en 2008 a 44,6 en 2010 (Barómetro de las Américas, 2010: 59). Actualmente México ocupa el último lugar de satisfacción con la democracia en América Latina con 19\% de satisfechos (Latinobarómetro, 2015: 36).

5 La participación electoral en el año 2000 fue de 63,9\%, en 2006 baja a 58,5\% repuntando en 2012 a 63,1\% (IDEA, 2014). La participación en protestas es de las más bajas en América Latina, solo el 3.8\% recurre a ellas (Barómetro de las Américas, 2013a: 81). Así, la proporción de quienes afirmaron que nunca las realizarían aumenta del 1\% en el período 2005-2009 a 64\% de 2010 a 2014 (Encuesta Mundial de Valores, 2014). En contraste, $24 \%$ de los mexicanos realiza algún tipo de labor comunitaria, equivalente a una de cada cuatro personas (Barómetro de las Américas, 2013a: 48). Asimismo, la participación en asociaciones de padres de familia creció de 22,2\% en 2008 a 22,30\% en 2012, mientras que en asociaciones de colonos y vecinos aumentó de 10,7\% a 13,35\%, respectivamente (Encup, 2008, 2012). Según Sedesol (2004), 54\% participa en juntas de vecinos y asociaciones de colonos y $12,4 \%$ en centros de padres de familia.

6 De 1989 a 1993, 22\% de los chilenos se inclinaban por las grandes diferencias de ingresos como incentivos, descendiendo a $10 \%$ de 1994 a 1998 y en los períodos subsecuentes (1999-2004 y 2005-2009) a 8\% y 7\%, respectivamente (Encuesta Mundial de Valores, 2014). De manera similar, la competencia entre individuos como estímulo para el trabajo durante los períodos 1994-1998 y 1999-2004 era de 19\%, reduciéndose a 15\% de 2005 a 2009 (Encuesta Mundial de Valores, 2014).

7 El 28,1\% de los chilenos concuerda con la idea de que en esencia la democracia supone que el Estado iguale los ingresos, frente al 4,3\% que está en desacuerdo (Encuesta Mundial de Valores, 2014). Asimismo, 26,1\% considera una característica democrática que los gobiernos utilicen los impuestos de los ricos para subsidiar a los pobres (Encuesta Mundial de Valores, 2014). 
Por su parte, la cultura democrática chilena se orienta más hacia las movilizaciones y protestas sociales que a la participación electoral ${ }^{8}$. De hecho, esta disminuye de manera importante sin que haya decaído el apoyo a la democracia, o sea, menor el interés en la política. Por el contrario, estos dos últimos aspectos se incrementan notablemente ${ }^{9}$.

No obstante, la paradoja está en que la cultura democrática chilena y las percepciones respecto de la desigualdad coexisten con la Constitución de Pinochet. Se trata de la presencia de lo que Garretón ha Ilamado la época pinochetista, caracterizada "por la existencia de un régimen democrático en el que gobierna una alianza de centroizquierda, que ha realizado avances sustantivos en los planos económico y social, pero en el que sigue vigente la institucionalidad heredada de la dictadura" (2008: 269).

\section{CONFIGURACIONES DISTRIBUTIVAS DEL ESTADO EN CHILE Y MÉXICO}

La constitución histórica de los Estados y su institucionalidad modulan las dimensiones culturales de la democracia y la desigualdad, pues el Estado participa de la producción de asimetrías independientemente del tipo de régimen político que adopte, pero cuando este es democrático despierta altas expectativas para reducirlas. Por tanto, las formas de proteger las ventajas de quienes más apoyan a los gobiernos y de cómo se extraen, se asignan y redistribuyen recursos (Tilly, 2000: 37), representan configuraciones sociopolíticas y distributivas útiles para contrastar cómo el neoliberalismo se impuso en Chile al calor de la dictadura quebrando el proyecto socialista de la Unidad Popular; mientras que en México se adopta durante la liberalización política del régimen autoritario y del agotamiento del modelo de desarrollo endógeno.

Obviamente, las configuraciones distributivas estatales contienen elementos previos al neoliberalismo y a las democratizaciones. En Chile, el derecho, la política y el sistema de partidos con espectro ideológico completo dejarán su impronta en dichas configuraciones. Primero porque pasada la independencia, gracias al derecho el gobierno se sometió a normas y plazos de término y además el caudillismo endémico en la cultura hispana no tuvo mayor acogida (Sepúlveda, 1985: 125). Después porque durante el siglo XX la particularidad de la política será su carácter más partidista que personalizado o populista (Garretón, 2010). Entonces, la política será la forma básica de constitución de la sociedad chilena (Garretón, 2008: 243), por lo que cuando se produce un conflicto central esta atraviesa todas las instancias (Garretón, 2008: 251), valiéndose del espectro ideológico completo que entraña proyectos

$8 \quad$ Chile es el quinto país con más participación en protestas de la región (11,1\%), rebasando la media estadística de 7,7\% (Barómetro de las Américas, 2013b: 88). La proporción de quienes realizaron alguna acción política no convencional pasó de 1\% en el período 2005-2009 a 16\% en 2010-2014 (Encuesta Mundial de Valores, 2014). Al mismo tiempo la participación electoral cayó de 90,6\% en el 2000 a 87,1\% en 2008 y hasta 41,9\% en 2013 (IDEA, 2014).

9 De 2008 a 2010 el apoyo a la democracia sube de 69,5\% a 76,1\% (Barómetro de las Américas, 2010: 41). Además, "Chile es el tercer país de la región donde más aumenta el apoyo a la democracia" (Latinobarómetro, 2013: 11) y donde el 60\% está satisfecho con ella (Barómetro de las Américas, 2010: 59). Asimismo, de 2005 a 2009 el 22\% declara estar interesado y muy interesado en la política, aumentando a 26\% de 2010 a 2014 (Encuesta Mundial de Valores, 2014). 
diferenciados respecto de la igualdad. Es así, porque lo que va a distinguir ser de izquierda o de derecha van a ser las expresiones a favor o en contra de la igualdad (Ansaldi, 2010: 25).

El reconocimiento al derecho como regulador de interacciones políticas va a inhibir el caudillismo y a dificultar que las redes políticas se oscurezcan, adopten dinámicas clientelares y produzcan desigualdad. No porque el derecho sea neutro al poder o porque no esconda intenciones distributivas -"prácticamente todas las leyes tienen consecuencias distributivas, por las que algunos grupos se benefician a expensas de los demás" (Stiglitz, 2012: 107)-, sino porque brinda a los actores certeza de los límites y las oportunidades en la disputa de recursos. De ahí su contribución al sistema de partidos, a la política y a la estabilidad. No es casual que el sistema político "se ordenara en torno a una ideología constitucionalista y profesionalizante" (Garretón, 2010). Sin embargo, aunque la ausencia de caudillos inhibió el clientelismo, mientras que el derecho fue clave para la política, los mecanismos de la desigualdad tendrán posteriormente uno de los dilatadores más contundentes de la historia chilena: la dictadura militar. Y sí, Chile es el caso paradigmático de imposición del patrón de acumulación basado en la valorización financiera por la vía dictatorial (Ansaldi, 2014: 24).

Creemos que entre los chilenos hay un acuerdo tácito que los hace apreciar lo legal por encima de lo ilegal e informal, aunque esa legalidad haya representado lo mismo al sustrato democrático plasmado en la Constitución de 1925 -"principal expresión política de la idea nacional-estatal-democrático-popular-partidaria" (Garretón, 2010)- que a un sistema de opresión y exclusión como la Constitución de Pinochet. En ambos casos, la norma sugiere legitimarse socialmente por el solo hecho de ser ley, es decir, su valoración reposa en una ficción que reconoce implícitamente a los ganadores y perdedores del proceso histórico de elección social que las configuró como tal.

Cómo explicar entonces que los enclaves dictatoriales persistan en democracia y que solo recientemente se estén desmantelando. Como ejemplos, las movilizaciones estudiantiles de 2006 contra el sistema educativo; el sistema electoral binominal ya modificado; la reforma laboral aún en debate; y la propia Constitución, cuyo reemplazo llegará hasta $2018^{10}$. Obvio que si la extracción, asignación y redistribución de recursos transitaba en un sistema en donde el "34\% de la votación obtenía la mitad de los escaños en el Congreso"11" (Garretón, 2011: 110), favoreciendo a la derecha, la desigualdad iba ser difícil de reducir. Dicho enclave dictatorial era un claro dilatador de la desigualdad, inserto en el núcleo de la representación política más formal con la que cuenta la democracia.

La aceptación tácita de la Constitución de Pinochet por los gobiernos concertacionistas evidencia tolerancia a la desigualdad que deviene del miedo a la polarización y del trauma

10 Concretarla requerirá siete etapas: educación cívica-constitucional; diálogos ciudadanos comunales y regionales; bases ciudadanas para la nueva Constitución; establecer mecanismos para elaborarla; enviarlos al Congreso; discutir y aprobar el mecanismo constituyente y el proyecto constitucional; convocar a un plebiscito (La Tercera, 14/10/15).

11 Para Bachelet "era un sistema concebido a partir del miedo a la libre determinación de las personas, a la representación plena, a la inclusión, a la mayoría, a la participación plena, a la competencia y a la plena democracia" (La Tercera, 27/04/15). 
a la violencia militar, junto con el aprecio social a las reglas por el estatus que alcanzan como leyes oficiales per se. La adaptación a la desigualdad que protagoniza la estabilidad política auspiciada por la Constitución explica las pautas que naturalizan las asimetrías, pues cuando la institucionalidad dictatorial es valorada positivamente, aquellas se normalizan y permanecen. De ahí que "el principal anclaje de la cultura de la desigualdad radique en la convicción, intensamente expresada, que señala la ausencia de factores estructurales" (Mayol, Azócar y Azócar, 2013: 129).

Sin embargo, la paradoja reaparece cuando recordamos que las aspiraciones igualitarias de ingresos son ascendentes y que las percepciones a favor del papel distributivo del Estado son superiores a quienes se oponen a ellas. Sospechamos que por debajo del aprecio a la estabilidad política y a la institucionalidad dictatorial sobreviven los anhelos igualitarios de la sociedad chilena, porque aquellas son valoraciones que evitan escalar el conflicto distributivo a nivel estructural, mientras que estos son escondidos y permanecen latentes en la subjetividad social, esperando por la oportunidad de configurarse en oposición a la desigualdad, no de manera generalizada, sino bastante acotada a ciertas contradicciones. En todo caso, hay que entender también que no es que las ideologías de la competencia y el individualismo contenidas en la Constitución de Pinochet no tengan cabida en la sociedad, sino que, como lo afirman Garretón y Cusmille (2002: 7), entre los chilenos no son aceptadas como un valor sino como una derrota.

En las dimensiones culturales de la democracia y la desigualdad, ciertos aspectos se hacen visibles al tiempo que se ocultan otros, sin que estos últimos necesariamente desaparezcan. Se trata de todo un sistema de selección que permite a las personas filtrarlos y que en Chile funciona gracias a la apuesta por la estabilidad política o por el miedo a la confrontación estructural entre las clases sociales. Por eso, la oposición a la desigualdad no será continua en el tiempo, ni abierta o generalizada hacia la totalidad de las herencias dictatoriales, sino muy específica. De hecho, se sabe que "la movilización social y política había decrecido progresivamente desde la década de 1990" (Garretón, 2003), sin que eso signifique que las nuevas modalidades de producción de la desigualdad en el sistema económico, como la subcontratación laboral, no estuvieran generando tensiones a las que posteriormente habrían de reaccionar los chilenos. Como lo afirman Ruiz y Boccardo (2014: 171), "desde 2006 en adelante quienes irrumpen más en la escena laboral no son los obreros tradicionales, sino aquellos sometidos a esa intermediación y que se encuentran en condiciones de extrema precarización".

En contraste, en México aunque la flexibilidad laboral existía de facto, es hasta 2012 cuando se legaliza con la reforma laboral, sin que esa situación sumada a la pérdida del poder adquisitivo del salario -que solo de 1969 a 2014 se estima es de 69,76\% (Esquivel, 2015: 30)- haya tenido gran oposición en el sector de los trabajadores. Por el contrario, desde hace más de dos décadas que las huelgas vienen en descenso, a diferencia de Chile en donde este tipo de acción colectiva oscila más o menos en el mismo número. 


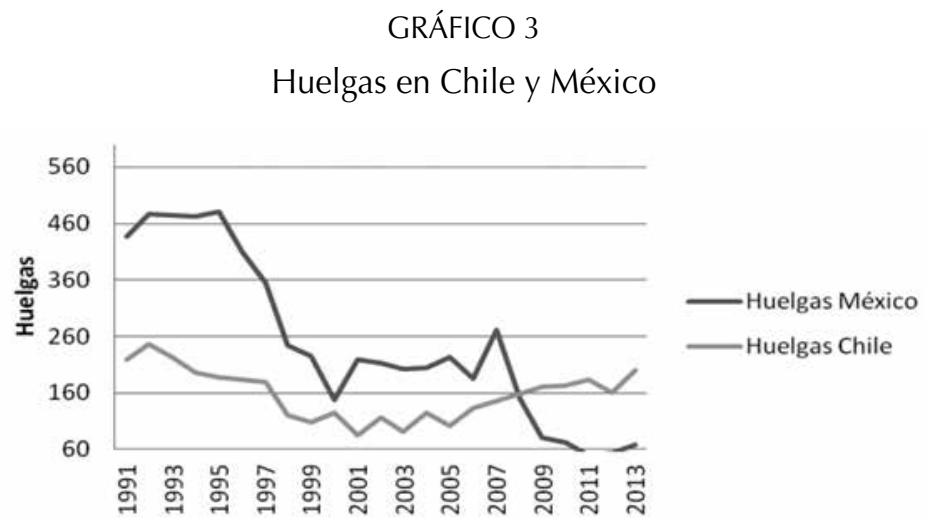

Fuente: Elaboración propia en base a Inegi (2013) y Dirección del Trabajo (2013).

Y es que México vive con pasividad las contradicciones del neoliberalismo que generan desigualdad, por ejemplo en el ámbito laboral ${ }^{12}$. Situación que podríamos explicar por la cercanía de los mexicanos al modelo de igualdad de oportunidades, pues sabemos de su proclividad a la competencia entre individuos como estímulo para el trabajo, y a las grandes diferencias de ingresos como incentivos de movilidad social. Ambas expresan la cultura de la desigualdad, aunque también sugieren una adherencia más ideológica que fáctica, pues en los hechos en México se trabaja mucho pero también se produce poco, es decir, al final los mexicanos no resultan ser tan competitivos ${ }^{13}$. Pero tampoco tan combativos como lo muestra el declive de las huelgas y la precariedad de la participación política, rasgos relevantes de su cultura democrática.

Dicha paradoja se remonta al modo en que se constituyó el Estado después de la Revolución y al impacto que esta tendrá en la cultura política mexicana, en términos de cómo se socializa políticamente bajo orientaciones personalistas y clientelares y cómo eso contribuyó a oscurecer las redes políticas y a insertarlas en la producción de la desigualdad. $Y$ es que la valoración social al personalismo y clientelismo va a permitir una forma de adaptación a la desigualdad que persistirá aun en democracia.

Recordemos que aunque México tuvo el momento más democrático de su historia en la Revolución, el caudillismo será constante en su sistema político. Particularmente, la reivindicación más radical de la democracia la expresó Zapata; para el líder campesino la democracia instaurada por Madero compartía una limitación con la dictadura porfirista: solo beneficiaba a los poderosos (Ansaldi, 2010: 200). Y sin embargo, aquel momento

12 Como si se tratara de una cualidad, el Presidente mexicano exclama: "hace casi 18 meses no ha estallado ninguna huelga federal en el país" (La Jornada, 24/03/15).

13 De los países de la OCDE, México es el último lugar en productividad laboral (IMCO, 2015:160) y donde más horas se trabajan anualmente (2.228 horas) (OCDE, 2012). 
democrático no incentivó un sistema de partidos fuerte e institucionalizado, en el que la política haya privilegiado la vía partidaria como sucedería en Chile.

En cambio, el personalismo de la política y la hegemonía del PRI serán fundamentales en las sucesiones presidenciales y en el sistema político de espectro ideológico partidario incompleto, donde no habrá confrontación de proyectos políticos del tipo izquierda-derecha a los que subyace cierto debate acerca de la igualdad ${ }^{14}$. Y es que durante este período las formas de representación política más primarias filtrarán el acceso a derechos sociales y políticos, mediante la pertenencia a las corporaciones estatales, organizadas en torno a los sectores obrero, campesino y de los trabajadores. Por eso, el valor que socialmente fue ganando el PRI estará en función de su contribución a la estabilidad política del país. Es decir, al PRI se le va a adjudicar haber ayudado a estabilizar a un México incendiado por las revueltas postrevolucionarias, poniendo fin a la época en que las luchas electorales se solucionaban con muertes dramáticas (Jiménez, Vivero y Báez, 2003: 382-383). Nos topamos con una gran diferencia entre Chile y México, pues lo que en el país andino lo logró el derecho, en México lo hará el PRI y su autoritarismo político.

El papel estabilizador del PRI explica la tendencia de la cultura política mexicana hacia el clientelismo y el personalismo, factores que favorecerán históricamente la adaptación a la desigualdad, pues las corporaciones estatales priistas condensaron los conflictos sociales distributivos logrando domesticarlos y porque ahí radica la socialización política de los mexicanos durante más de setenta años. Esa valoración implica cierto privilegio por la informalidad en las prácticas políticas, que se sitúa por encima de aquellas apegadas a la institucionalidad legal. Se trata del oscurecimiento de las redes políticas, donde las interacciones entre actores se dan de manera oculta e incluso con actores ilegales. De ahí que las lealtades políticas mezcladas con intereses privados e ilegales se instalen en el sistema político y en la cultura de la desigualdad.

Entender lo que sucede en México implica admitir que en su sistema político está enraizado el narcotráfico. Luis Astorga (2009) refiere que el sistema de partido de Estado creado después de la revolución protegió y contuvo a los traficantes. Es decir, "el tráfico de drogas nació subordinado a la política desde los tiempos de la revolución, se reforzó en el estado posrevolucionario dominado por el partido de Estado [...] y así continuó durante siete décadas" (Astorga, 2014: 232). Dicha subordinación parece una contribución adicional del PRI a la estabilidad, pues esa capacidad de concertar con el narcotráfico se perderá durante la transición a la democracia, particularmente con la alternancia política municipal, seguida de la estatal y la federal. Fue así como los pactos de convivencia se desintegraron con la democratización introduciendo niveles sin precedentes de fragmentación y discordancia dentro del sistema político (Briscoe, 2014: 41).

14 Aunque el nacimiento de las principales expresiones políticas de izquierda y derecha data de 1919 y 1939 , respectivamente, su oposición fraguará hasta fines de los ochenta y con mayor fuerza durante los noventa. 
La estabilidad política atribuible al PRI por haber apaciguado la violencia postrevolucionaria, por su labor domesticadora de los conflictos distributivos y por la subordinación de los actores ilegales al sistema político, serán factores que dilatarán la desigualdad y tendrán, asimismo, amplia aceptación social por el aprecio que suscita la habilidad priista de contener y gestionar casi cualquier clase de crisis. Así, la configuración de los procedimientos distributivos del Estado postrevolucionario dejarán su huella autoritaria en la transición a la democracia, aunque esa herencia se va a resignificar en el nacimiento de la cultura democrática, pues "la política pone en interacción y tensión las convicciones, los sentidos y las atribuciones de la cultura, dinamizando sus contenidos" (Tejera, 2009: 250). Específicamente, los contenidos políticos más dinamizados con la transición serán los procesos electorales, su afinamiento y sofisticación materializados en reformas institucionales.

Ese rasgo distintivo de la cultura democrática de los mexicanos les jugará en contra cuando el neoliberalismo endurezca la desigualdad. Para entonces estarán mal parados, su cultura política no habrá integrado sólidamente los valores igualitarios de la democracia, ingredientes que posibilitan la agencia social para oponerse a la desigualdad. En cambio, van a estar más ocupados de organizar las competencias políticas que de reflexionar cómo la liberalización del sistema político podía haber favorecido el combate a las asimetrías económicas. No es que no existieran aspiraciones por mayor igualdad, sino que esas apreciaciones de la subjetividad social no escalaron a prácticas políticas concretas. Muy a pesar de que "en América Latina, el ethos democrático ha estado mucho más cerca del ideal igualitario, comunitario e integrativo, que del libertario e individualista" (Garretón, 2012: 157), creemos que esa realidad corresponde más a la experiencia chilena que a la mexicana. Finalmente, los contrastes entre México y Chile representan tendencias de procesos históricos particulares a cada nación, pero hay otros que les son comunes, aun cuando estén más arraigados en un país que en otro, como la corrupción cuyo impacto estructural habremos de integrar a nuestro esfuerzo por desentrañar las paradojas de las dimensiones culturales de la democracia y la desigualdad.

\section{CORRUPCIÓN: CONTRIBUCIONES DE LA INJUSTICIA DISTRIBUTIVA A LAS DIMENSIONES CULTURALES DE LA DEMOCRACIA Y LA DESIGUALDAD}

Es sabido que el funcionamiento del sistema capitalista no responde a la racionalidad de los intercambios económicos, cuyo cálculo de oferta y demanda o de eficiencia en los procesos de producción se autorregulan por instituciones neutras a los poderes políticos o fácticos. Bajo ninguna forma de desarrollo que haya tenido el capitalismo y bajo ningún régimen político que lo amparara, la dinámica económica se mantuvo al margen de procesos ilegales de acumulación de riqueza, que no necesariamente aluden a la explotación aunque se relacionan con ella. A diferencia del funcionamiento de este mecanismo generador de desigualdad, soportado normativamente en legislaciones laborales de corte neoliberal y en sus respectivas corrientes ideológicas con capacidad de legitimarlas, los procesos ilegales de acumulación se desenvuelven bajo lógicas informales ocupando institucionalidades políticas como fachada, para facilitar la interacción de redes oscuras que terminan dilatando la desigualdad. 
Se trata de la corrupción y de los principios de injusticia distributiva con los que opera y a los que las sociedades son siempre sensibles, ya sea rechazándolos o adaptándose a ellos mediante valoraciones funcionales. La corrupción tanto en México como en Chile se ha nutrido históricamente del movimiento de las estructuras políticas a diferentes escalas y con distintos grados de alcance. Esto es, con el cambio y/o quiebre en la alineación y conformación de los poderes políticos. Por ejemplo, en Chile aparece con fuerza en la dictadura militar, pues es "cuando el sistema de control y equilibrios, propios de la separación de poderes, desaparece y es reemplazado por la concentración de todos los poderes en el Ejecutivo" (Orellana, 2007: 259), mientras que en México se sitúa en el proceso de subordinación de los actores ilegales al PRI, al Estado posrevolucionario y a su concentración de poder.

Esas formas de corrupción que han ligado al Estado y al sistema económico, permitiendo a ciertos sectores y actores amasar fortunas de distinto tamaño, aun en contextos de crisis, evidencian cómo las fronteras ilegales e informales de la política y la economía suelen desdibujarse, abigarrándose al interior de las esferas legales del Estado. La magnitud de esta tendencia no será la misma que se observa al interior de los sectores sociales empobrecidos. Ahí, la debilidad en el mundo del trabajo es la que empuja a otros modos de acceso al dinero y a las prestaciones sociales (Kessler y Merklen, 2013: 15) ${ }^{15}$. En cambio, entre quienes ocupan posiciones económicas y de poder más altas la corrupción no va a responder a la satisfacción de necesidades básicas, sino a verdaderos sistemas de acumulación de riqueza y privilegios que se valen de los reacomodos en las estructuras políticas, pues es ahí donde encuentran legitimidad.

Por eso son de larga duración y hallamos evidencias de su presencia estructural en el Estado, en la economía y en la producción y reproducción de la desigualdad. Particularmente, la entrada del neoliberalismo en Chile incrementó las asimetrías económicas, no solo porque se privilegiaron los derechos del capital financiero por encima de los derechos de los individuos y de las colectividades, sino por la corrupción del régimen militar. En esa época Pinochet traspasaba recursos públicos a sus cuentas bancarias, transfería empresas públicas a manos privadas, pagaba sobresueldos e indemnizaciones a políticos con altos cargos y además los propios militares organizaban el contrabando de armas (Orellana, 2007: 258-259). En contraste, en México la corrupción se cobijó bajo la ideología nacionalista revolucionaria propia del Estado corporativo, acompañada de los pactos de convivencia con actores ilegales. Será solo hasta mediados de los años ochenta, en el contexto del tránsito hacia la democracia electoral, que dicha ideología comenzará a ser desplazada por el paradigma neoliberal.

Ya en democracia y con el neoliberalismo instaurado, las prácticas de corrupción van a exhibir exóticas mixturas que entrecruzan ideas de eficiencia y productividad, casi como obligaciones morales para el mundo de las empresas y para el Estado, junto con el tráfico de

15 Eventualmente en la provisión de bienes y servicios de estas clases hay un deslizamiento hacia el delito que se combina con actividades lícitas, sin que por fuerza y en todos los casos las personas se instalen en la delincuencia de una vez y para siempre. 
influencias y negociaciones políticas informales. A la par, las consignas de la no intervención estatal en la economía -"salvo para regular la competencia"- exhiben a contrapelo el uso ilegal de recursos privados para financiar actividades políticas que son en apariencia de carácter público. Aunque también ocurre a la inversa, con la asignación de recursos públicos que favorecen a entidades privadas a cambio de lealtades y favores políticos varios.

Por tanto, los procesos de democratización cambiarán las formas de corrupción derivado del movimiento de las estructuras políticas, aunque aquellas serán más profundas en México por los rasgos clientelares y personalistas de la cultura política, así como por el ethos libertario de la democracia, orientado hacia la competencia partidista. En ese sentido, en México "se pensó que los partidos se convertirían en los mejores vigilantes y contrapesos de sus adversarios y que serían un dique contra la corrupción; que se fiscalizarían celosamente los unos a los otros y que se cuidarían en el ejercicio del poder si no por responsabilidad ética pública al menos por interés: por miedo a que una vez perdido el puesto el sistema de justicia los alcanzara" (Casar, 2015: 23-24), sin embargo no fue así. En cambio en Chile, aunque la corrupción estará protagonizada por los partidos políticos, tendrán un arraigo cultural ambiguo, en tanto el ethos democrático chileno es más cercano al ideal igualitario. Esto significa que la corrupción en Chile pasa por el sistema político, pero no se arraiga en la cultura democrática porque el valor predominante no está asentado en la competencia política, sino en ideales sociales más de carácter integrativo, comunitario e igualitario.

Ciertamente, en Chile la corrupción ha exhibido vínculos con el sistema político: son conocidos los casos Dávalos y Penta, que pusieron al descubierto, por un lado, el uso de información y posiciones políticas privilegiadas para aumentar ganancias personales bajo la complicidad de una red política oscura con nodos distribuidos en todo el espectro ideológico partidario y, por otro, a un sistema de defraudación fiscal y de financiamiento ilegal de campañas electorales. Un hecho que confirma los dichos de destacados líderes políticos, quienes "en 2007 reconocieron que los partidos políticos de gobierno financiaban sus campañas con fondos fiscales, que a través de diversos procedimientos desviaban de sus objetivos sociales, para traspasarlos a las arcas partidarias o a sus bolsillos personales" (Orellana, 2007: 258-259). No obstante, desde fines de los años noventa la cultura democrática chilena dejó de tener al sistema partidario como referente central para hacer política, muestra de ello es el distanciamiento de los movimientos sociales con los partidos políticos. Según Garretón (2008:264), los movimientos estudiantiles, juveniles, ecológicos, regionales, étnicos, de género u orientación sexual no necesitan a la política partidaria para existir, aunque después la necesiten para materializar sus demandas.

Esa distancia supone que la cultura democrática chilena tiene otros referentes no articulados con las formas de corrupción auspiciadas por los partidos políticos. Siendo de diferente naturaleza, pudieron conservar ideales de igualdad social. Un ejemplo de esto lo encontramos "al final de la década de los noventa, en el llamado 'malestar chileno', una crítica ideológica, esencialmente protagonizada por intelectuales, en contra de la dominación de los valores del mercado y a partir de la constatación de la pérdida de la identidad nacional, la solidaridad social y el proyecto colectivo" (Castells, 2004: 148). 
Sin duda y sin perder de vista las diferencias entre México y Chile, es en el plano partidario donde particularmente "la corrupción deja entonces de ser un acto aislado e ilegal, para convertirse en una forma institucionalizada de mediación de intereses que se sustituye o coexiste con otras instituciones, muchas de ellas democráticas" (Aureano y Ducatenzeiler, 2002: 86). En términos generales, es ahí donde operan los criterios de injusticia distributiva que no responden al valor democrático de la igualdad, sino a los de la desigualdad. Esto es, a la concentración de recursos económicos y a la discrecionalidad en su manejo; a la opacidad en las interacciones entre actores que permite la acumulación sistemática de ventajas; a las lealtades y alianzas políticas negativas que en conjunto son capaces de amplificar la explotación, la exclusión y el acaparamiento de oportunidades. Pero como lo muestra el caso mexicano, al estar investidas de democracia electoral Ilegan a habilitar amplios ámbitos de permisividad social.

De no ser así, no podríamos explicar por qué, aunque la democracia electoral mexicana atrajo mayor distribución del poder político, este nunca superó totalmente los rasgos personalistas y clientelares de la cultura política posrevolucionaria y por tanto tampoco se alejó de la corrupción. En todo caso esta se pluralizó con la democracia, pero nunca desapareció ni como horizonte de posibilidades de mejora personal o sectorial, ni como práctica política. Esa es la influencia más grande de la corrupción respecto de las dimensiones culturales de la democracia y la desigualdad, pues las orientaciones de la precaria participación política hacia las cuestiones distributivas responden a la imposibilidad de resolver las asimetrías socioeconómicas por la vía de la competencia y la representación políticas, pues es en su interior donde se dilatan, sin que los actores políticos o los actores privados y mucho menos los ilegales sean juzgados.

Así, otra gran diferencia que exhibe el funcionamiento de la corrupción como dilatador de la desigualdad entre estos países es el grado de impunidad con el que particularmente en México ocurren este tipo de prácticas. Según Casar (2015: 57), de 444 denuncias presentadas ante la Procuraduría General de la República en 15 años, solo hubo 7 consignaciones, equivalentes al 1,6\%. En contraste en Chile, solo en el período de enero a marzo de 2015 ingresaron a la Fiscalía 627 delitos de corrupción, de estos resultaron 327 personas imputadas y donde las condenas ascienden a 59, lo que equivale al 9,4\% del total de este tipo de delitos (Fiscalía de Chile, 2015).

La distancia es abismal y no podría ser de otra manera. Ya las trayectorias de la historia sociopolítica de cada país nos lo han explicado y ahora nos ayudan a entender su posición en el ranking internacional de la corrupción. Según el Índice de Percepción de la Corrupción de Transparencia Internacional (2015), el lugar de Chile desde 1995 y hasta 2014 oscila entre el 17 y el 23, con calificaciones que van del 68 al 75 (considerando una escala de 0 a 100, en la que entre más alta es la calificación menor es el nivel de corrupción percibido en el sector público). En contraste, México ha pasado del lugar 38 al 103 en el mismo período, con calificaciones entre 26 y 37. 


\section{GRÁFICO 4}

Evolución del Î́ndice de Percepción de la Corrupción

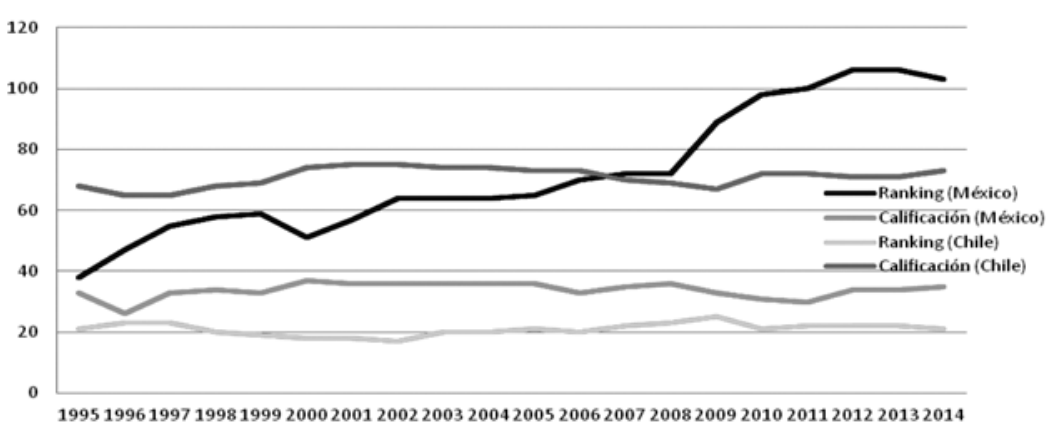

Fuente: Elaboración propia con datos de Transparencia Internacional (2015).

La potencia de la corrupción como dilatador de la desigualdad es mayor en México que en Chile. No obstante, la corrupción está relacionada con otro factor que hemos anticipado, impacta también en las dimensiones culturales de la democracia y de la desigualdad, haciendo que el contraste entre ambos países aumente. Se trata de la violencia. Según el Institute for Economics and Peace (2015c: 2), existe una relación estadísticamente significativa entre la paz y la corrupción, en donde una vez que determinado país alcanza cierto nivel de corrupción, hay un punto de inflexión que provoca que con un pequeño aumento de esta disminuya sensiblemente la paz.

La relación corrupción-violencia se explica por la dinámica de las redes políticas oscuras. Recordemos que "la corrupción política es una de las principales estrategias de las redes ilícitas para poder llevar a cabo sus actividades económicas" (Bucher, 2014: 21), mismas que incrementan la desigualdad. Pero además hay que tener presente que "las conexiones entre políticos y redes criminales se presentan tanto en países con sistemas democráticos como en democracias frágiles" (Bucher, 2014: 21) como la mexicana, que a diferencia de la chilena exhibe notorias cargas de violencia.

\section{VIOLENCIA, CULTURA DEMOCRÁTICA Y CULTURA DE LA DESIGUALDAD}

La violencia es clave dentro de la compleja relación entre la cultura democrática y la cultura de la desigualdad, pues América Latina no solo es la región económicamente más desigual del mundo, sino que "tiene la tasa de homicidios más alta en comparación con cualquier otra región en la Tierra (23 homicidios intencionales por cada 100.000 habitantes)" (Barómetro de las Américas, 2014a: 4). No obstante, hay diferencias importantes de nación a nación; Chile por ejemplo "mantuvo su posición como el país más pacífico de la región" (Institute for Economics and Peace, 2015b: 12), en cambio el nivel de paz de México en 2014 se acercó a los niveles de 2007, cuando el homicidio y los delitos violentos comenzaron a aumentar rápidamente" (Institute for Economics and Peace, 2015a: 2). 
En principio, el efecto directo que genera la violencia en la cultura democrática se observa cuando "las personas buscan la reparación de la violencia en el ámbito político a través de cambios en los patrones de participación" (Barómetro de las Américas, 2014a: 74). Significa que "cuando se sienten amenazadas o inseguras son más propensas a tolerar, e incluso a apoyar a gobiernos que restringen algunos derechos políticos fundamentales y libertades públicas" (Barómetro de las Américas, 2014a: 3). En ese sentido, encontramos que $50 \%$ de los mexicanos apoya medidas como un golpe de Estado por militares, en situaciones de alta corrupción o delincuencia (Barómetro de las Américas, 2014b: 159), mientras que $68 \%$ de los chilenos cree que un golpe de Estado nunca es justificable (Barómetro de la Política, 2015). De ahí que el apoyo concedido al rol militar en tareas de seguridad pública en México sea de 76\%, frente al 54,9\% registrado en Chile (Barómetro de las Américas, 2014a:105).

Las diferencias se explican por las respectivas trayectorias sociohistóricas y sociopolíticas de cada país, en las que, como sabemos, el Estado ha participado de la violencia ilegal e ilegítima por medio de redes políticas oscuras. En Chile este tipo de participación estatal se dio durante la dictadura militar y cesó con la democratización. México, por su parte, ha sufrido la actividad violenta de las redes políticas oscuras, lo mismo durante el régimen autoritario priista que durante el desarrollo de la democracia electoral. Violencia de la que, por cierto, ahora también son partícipes los partidos de izquierda ${ }^{16}$.

Cuando las redes oscuras de la política se enquistan en el Estado, las consecuencias negativas en la interacción social cotidiana, en la confianza con el otro, en el uso de espacios públicos, así como en la distribución de recursos, crecen exponencialmente. Partimos de la idea de que la violencia determina considerablemente los hábitos de vida, de desplazamiento, las maneras de conversar, así como el conjunto de las prácticas sociales dando lugar a una recomposición total de los modos de vida (Crettiez, 2009: 52-53). Por lo que si hemos de ubicar algún impacto de la violencia en las dimensiones culturales de la democracia y la desigualdad, debe ser también en los espacios públicos, pues ahí el miedo a la delincuencia y la victimización por crimen tiene efectos transformadores en las rutinas de los ciudadanos, en los planes y los sentidos de bienestar. Por ejemplo, la gente puede cambiar los lugares que frecuenta o las rutas que utiliza para el transporte (Barómetro de las Américas, 2014: 29).

La importancia del impacto de la violencia en los espacios públicos no radica tanto en el supuesto de que estos habilitan la construcción de capital social, es decir, no descansa solo en su posibilidad de fomentar la inclusión social y el civismo, o bien de contribuir a la cohesión social (Vargas y Merino, 2012: 898), sino sobre todo en el hecho de que expresan y cristalizan las contradicciones propias de la desigualdad, por lo que al inhibirse sus usos y apropiaciones se vuelven invisibles los conflictos distributivos de la sociedad, dificultando su procesamiento democrático.

16 Es conocido internacionalmente el caso de la desaparición de 43 estudiantes normalistas, en el que está involucrado el expresidente municipal de Cocula, perteneciente al Partido de la Revolución Democrática. 
Por eso, al descubrir que la percepción de inseguridad en México aumenta cuando el lugar donde se experimenta es público, es que se incrementa también la probabilidad de que las asimetrías económicas se invisibilicen y en consecuencia la oposición a ellas sea débil. En ese sentido, con excepción de los bancos, sitios como los parques o centros recreativos, la calle, el transporte y los cajeros automáticos en la vía pública son en proporción donde las personas perciben más inseguridad, comparada con la que sienten en espacios más de carácter "privado" como la casa o los centros comerciales (ENVIPE, 2014).

\section{GRÁFICO 5}

Percepción de inseguridad en México

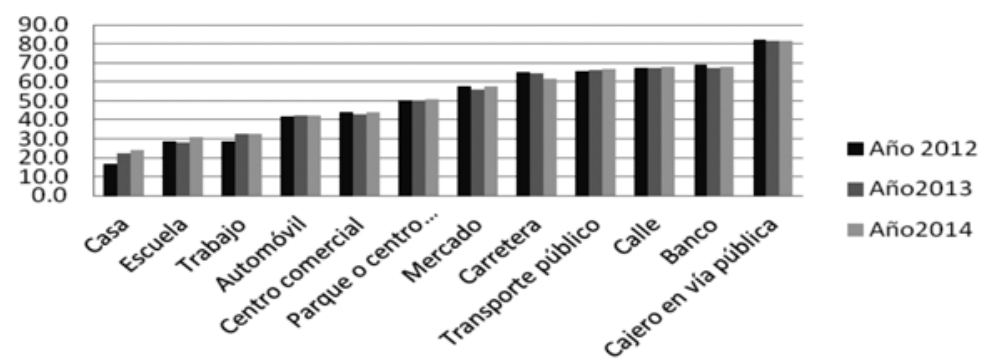

Fuente: Elaboración propia con datos de ENVIPE (2012, 2013, 2014).

En contraste, en Chile la sensación de inseguridad es elevada solo en ciertos espacios públicos. Por ejemplo, la calle y los micros concentran la mayor proporción de sensación de inseguridad, frente al barrio o la comuna que exhiben la situación opuesta. Y no obstante la sensación de inseguridad en la calle ha disminuido en años recientes y en cambio es en las discotecas donde más creció (ENUSC, 2014).

\section{GRÁFICO 6}

Sensación de inseguridad en Chile

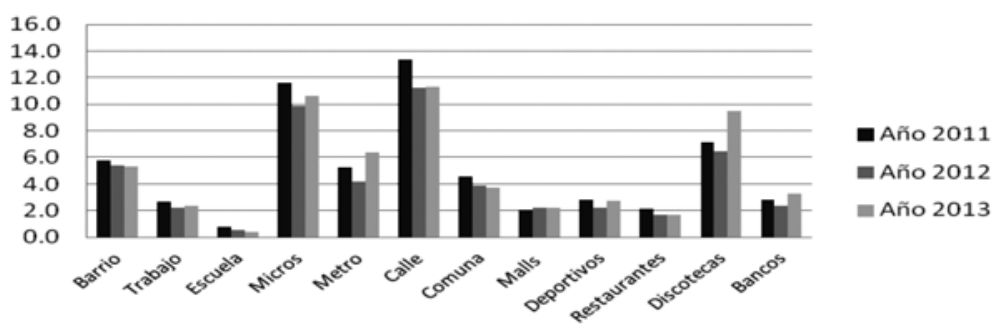

Fuente: Elaboración propia con datos de ENUSC (2011, 2012, 2013).

La violencia inhibe comportamientos sociales y altera la interacción social, el contacto con el otro y las posibilidades de empatía social para enfrentar a la desigualdad. En otras 
palabras, la violencia provoca una forma de exclusión que alienta la desigualdad, pues trastoca las disposiciones hacia la solidaridad, sobre todo porque en democracias con alta densidad de redes políticas oscuras, las sanciones a las acciones colectivas que eventualmente pudieran reaccionar a las asimetrías socioeconómicas suelen ser graves, esto es, llegan a costar hasta la vida.

De ahí que la participación en asuntos públicos y otros tipos de involucramiento con la comunidad que no son necesariamente de corte político, sino lúdicos, religiosos o artísticos, se vean erosionados. Muestra de ello es cómo en México, a causa del miedo, el 69,6\% de las personas no deja que sus hijos menores de edad salgan, 34,1\% evita salir a caminar, $33,1 \%$ ha dejado de visitar parientes o amigos y $29 \%$ de ir al cine o al teatro (ENVIPE, 2014). Por su parte, en Chile el 63,4\% prefiere no salir de noche, 60,8\% evita dejar sola la casa, mientras que 65,2\% evita llegar muy tarde al hogar (ENUSC, 2014). Luego entonces, aunque idealmente "las democracias minimizan ese miedo, sellando un pacto de no violencia entre los gobernantes y sus rivales y otros oponentes potenciales" (Keane, 2002: 16), no siempre lo consiguen.

Es importante señalar que las diferencias en las preguntas y en las respuestas captadas por las encuestas citadas dan cuenta de que la violencia en Chile inhibe aquellas conductas cercanas al ámbito personal e individual, mientras que en México se evitan más las de carácter colectivo y social. En realidad, esto responde a que hay cierta clase de violencia que impera más en una sociedad que en la otra. En ese sentido, las dimensiones culturales de la democracia y la desigualdad se ven alteradas por la convergencia de al menos dos violencias: la social y la política. Se distinguen por sus objetivos, es decir, por hacia dónde, hacia qué o hacia quiénes se dirigen, así como por el estatus de los actores que las practican y su discurso de justificación (Crettiez, 2009: 22). En ambas el Estado juega un papel central por las capacidades diferenciadas que posee, tanto para gestionarlas como para producirlas. Tratándose de la violencia política, hemos visto que moviliza una configuración perversa entre legalidad-ilegalidad-informalidad, que es característica del funcionamiento de las redes oscuras de la política, cuya influencia en la cultura democrática queda expuesta también cuando "los gobernantes son electos y responden parcialmente a los ciudadanos, pero también a los actores ilegales y a intereses políticos particulares, manteniendo apoyos ambivalentes a la democracia" (Alvarado, 2012: 32).

Asimismo, intuimos una relación entre la violencia social y la cultura de la desigualdad, pues la violencia tiene tres fuerzas originarias: la competencia, la desconfianza y el honor (Sebesta, 2014: 89) ${ }^{17}$, lo que quiere decir que las sociedades que muestran mayor competencia entre las personas y en las que impera la desconfianza en el otro no solo son propensas al individualismo y en consecuencia a la desigualdad, sino que resultan también ser más violentas. Así se explica por qué una sociedad como la mexicana, que apuesta por la competencia

17 El argumento original pertenece a Thomas Hobbes y es recuperado por la autora. 
individual para superar la desigualdad ${ }^{18}$ y además registra niveles de desconfianza interpersonal por debajo del promedio en la región $-59 \%$ frente al 67\% registrado en Chile (Barómetro de las Américas, 2014b: 171-172)-, es al mismo tiempo una de las más violentas. Y es que la violencia dilata la desigualdad, pues como lo expone Crettiez (2009: 55), dentro de las razones de la violencia está la búsqueda de lucro, es decir, la violencia paga.

Dentro de la relación que estamos describiendo es clave establecer que la violencia se produce con mayor frecuencia cuanto más se profundiza la diferencia entre las aspiraciones y el cumplimiento de las expectativas (Crettiez, 2009: 44). Por ejemplo, cuando las aspiraciones de mayor igualdad no se materializan. Una vez más el caso de México es ilustrativo, pues la sociedad anhela mayor igualdad económica, pero no la consigue ni parece proyectarla por vía de la política institucional, ni por la de las movilizaciones sociales u otros tipos de acción colectiva. Probablemente, no solo por las razones históricas que hemos expuesto, sino también por el impacto que tiene el miedo en la economía. En ese sentido, el miedo derivado de la violencia puede potencialmente alterar la participación en la economía (Institute for Economics and Peace, 2015a: 53).

Pese a que se afirma que la violencia en México no está estadísticamente vinculada a las desigualdades en la riqueza (Institute for Economics and Peace, 2015a: 48), nosotros sostenemos que sí, pues generalmente en esos análisis estadísticos se considera la distribución del ingreso -ocupando los datos de encuestas de ingreso y gasto en los hogares-confundiéndola con la distribución de riqueza. Ya Piketty (2014: 363) ha explicado que los resultados del uso de esa clase de instrumentos contribuyen a dar una visión sesgada y falsamente tranquilizadora de la distribución de la riqueza ${ }^{19}$.

Finalmente, esta relación entre la violencia y la cultura de la desigualdad no es causal ni mecánica, sino mediada por los factores históricos analizados. Sin duda, la violencia influye porque provoca miedo, y el miedo no es aliado de la libertad, le roba al sujeto su capacidad de actuar con o contra otros, y peor aún, porque cuando grandes masas se ven envueltas en las oscuras nubes del miedo, el sol se apaga para la sociedad civil (Keane, 2002: 22), o cuando menos no la alumbra con la misma intensidad, volviendo más difícil su oposición democrática a las injusticias de la desigualdad.

\section{CONCLUSIONES}

El recorrido por las dimensiones culturales de la democracia y la desigualdad en México y Chile nos permitió articular los matices más evidentes de las trayectorias históricas de sus

18 El $72,4 \%$ de los mexicanos piensa que la gente solo se ocupa de sí misma, contra $26,3 \%$ que opina que frecuentemente ayuda a los demás (Encup, 2012: 20).

19 Esquivel (2015: 14) midió en México la distribución de los ingresos en el decil superior haciendo un ajuste entre las encuestas de ingreso en los hogares y las cuentas nacionales. El resultado: un ingreso 60\% más elevado en comparación con la medición tradicional que sería cercana al 45\%. Es decir, la concentración del ingreso en el decil más alto es exactamente contraria a la que se obtiene ocupando datos originales de las encuestas de ingreso y gasto en los hogares. 
sociedades, tanto en términos políticos como económicos e incluso ideológicos. Recordemos los papeles del derecho en el caso de Chile y de la cultura nacional revolucionaria en México como estabilizadores políticos y su influencia histórica sobre las formas de participar de la disputa y distribución de recursos económicos.

Dentro de los aspectos relevantes que marcan la diferencia entre estos países están el clientelismo y el personalismo político. Ejemplos del oscurecimiento de las redes de la política que, desarrollados más en México que en Chile, han implicado no solo que la desigualdad se dilate sino que las personas se adapten a ella, ya que, como prácticas y características políticas informales de la democracia mexicana, establecen intercambios asimétricos que son valorados, porque "aun cuando analíticamente estas relaciones sean desiguales, tienden a ser imaginadas por quienes las practican como sustentadas en intercambios ubicados en el ámbito de las relaciones equivalentes personales" (Tejera, 2009: 257).

Destaca por otro lado el apego al derecho de los chilenos, que actúa también como dilatador de la desigualdad, no solo porque "la obsesión por el orden da pie a la dictadura de Pinochet" (Lechner, 2002: 60), sino porque cuando la institucionalidad dictatorial es apreciada positivamente logra neutralizar los conflictos distributivos de la sociedad a nivel estructural. Ciertamente, el contrapeso a este problema descansa en el ethos democrático chileno, enraizado en valores igualitarios que fueron vehiculados inicialmente por el sistema de partidos, aunque después estos dejaran de ser el eje de la socialización política de los chilenos. En contraste, el ethos democrático mexicano enfocado obsesivamente a la competencia político-electoral va a carecer de la capacidad de gestar y traducir ideales de igualdad en prácticas sociopolíticas que logren abatir las asimetrías económicas, porque el aprendizaje para hacer política tiene como referente inicial el partido de Estado y, en el mejor de los casos, las estructuras políticas paralelas que surgieron junto con los programas antipobreza en la época de la liberalización política.

Sin duda otro factor que incide no solo en México sino también en Chile es la corrupción, que dilata la desigualdad y adquiere una legitimidad gracias a aquello que Kessler y Merklen (2013: 19) denominan movilidades laterales, en donde un mismo actor, una misma mercancía en momentos diferentes, puede pasar de lo legal a lo ilegal para más tarde otra vez ser legalizado. Así el botín obtenido, que beneficia en mayor o menor medida a los nodos de las redes políticas oscuras, va circulando y en esos desplazamientos se arropa con investiduras políticas y/o empresariales que lo convierten de nueva cuenta en bienes, recursos y capitales económicos. Por tanto, aunque el origen de las ganancias provenga de profundas injusticias distributivas, se re-ciclan, esto es, se insertan en nuevos ciclos socioeconómicos con la complicidad de políticos, funcionarios públicos y empresarios, así como con la participación a veces tácita de la sociedad.

Finalmente, la corrupción y la violencia contribuyen al alejamiento de las personas del sistema político por desconfianza, y porque las redes oscuras con las que operan son cerradas y como tales solo distribuyen las excelsas magnitudes de beneficios y privilegios entre sus miembros. Es ahí donde radica la injusticia distributiva, cuyos criterios de asignación se distancian de la igualdad o de la necesidad y/o merecimiento e incluso de las cargas 
sociales que se imponen a quienes pertenecen a esa clase de redes. En cambio, se sujetan a las capacidades de influencia, lealtades políticas, chantaje y violencia que cada uno de los nodos posee, alterando las percepciones de la desigualdad y el sentido igualitario de la democracia.

\section{BIBLIOGRAFÍA}

Alvarado, A. (2012): Violencia y democracia. Balance de los estudios sobre violencia, Estudios Sociológicos, 30.

Ansaldi, W. (2010): No es que la democracia esté perdida: está bien guardada y mal buscada, Revista Latinoamericana de Ciencias Sociales, 2 (3).

(2014): De la vox populi, vox deus, a la vox populi, vox mercatus. La cuestión de la democracia y la democracia en cuestión, Revista del Centro de Estudios Avanzados, 31.

Astorga, L. (2009): México: transición democrática, organizaciones de traficantes e inseguridad, Razón pública, disponible en http://www.razonpublica.com/index.php/internacional-temas-32/173mco-transiciemocrca-organizaciones-de-traficantes-e-inseguridad.html

(2014): Opciones de la clase política frente a la delincuencia organizada en México, en C. Niño: Anuario 2014 de la seguridad regional en América Latina y el Caribe, Friedrich Ebert Stiftung, Bogotá.

Auerano, G. y G. Ducantenzeiler (2002): Corrupción y democracia: algunas consideraciones a partir del caso argentino, Revista Mexicana de Sociología, 64.

Barómetro de las Américas (2010): Cultura política de la democracia en Chile, 2010, Vanderblit University.

(2013a): Cultura política de la democracia en México y en las Américas: Hacia la igualdad de oportunidades, Vanderblit University.

(2013b): Cultura política de la democracia en Chile y en las Américas: Hacia la igualdad de oportunidades, Vanderblit University.

(2014a): The political culture of democracy in the Americas, 2014: Democratic governance across 10 Years of the Americas Barometer, Vanderblit University.

(2014b): Cultura política de la democracia en México y en las Américas, 2014: Gobernabilidad democrática a través de 10 años del Barómetro de las Américas, Vanderblit University.

(2015): La imagen de Pinochet y la dictadura, Market Opinion Research International, Santiago.

Briscoe, I. (2014): Evolución histórica de los nexos entre política, delito y economía en América Latina, en I. Briscoe, C. Perdomo y C. Uribe: Redes ilícitas y política en América Latina, IDEA, Netherlands Institute of International Relations, Estocolmo.

Burcher, C. (2014): Introducción, en I. Briscoe, C. Perdomo y C. Uribe: Redes ilícitas y política en América Latina, IDEA, Netherlands Institute of International Relations, Estocolmo.

Casar, M.A. (2015): México: anatomía de la corrupción, CIDE, IMCO, México D.F.

Castells, M. (2004): Estado y sociedad en la democracia chilena, Estudios de Política Exterior, 18 (100).

Comisión Económica para América Latina y el Caribe (CEPAL) (2014): Panorama social de América Latina 2014, CEPAL, Santiago. 
Cortés, F. (2013): Medio siglo de desigualdad en el ingreso en México, Economía, 10 (29).

Crettiez, X. (2009): Las formas de violencia, Waldhuter Editores, Buenos Aires.

Dirección del Trabajo (2013): Compendio estadístico, Departamento de Estudios de la Dirección del Trabajo, Santiago.

El Mercurio (2014): Familias del 20\% más pobre muestran el mayor aumento de ingresos y cae la desigualdad en el país, 10 de diciembre.

Encuesta de Caracterización Socioeconómica Nacional (CASEN) (2014): Ministerio de Desarrollo Social del Gobierno de Chile, disponible en http://observatorio.ministeriodesarrollosocial.gob. cl/casen_usuarios.php (consultado el 19 de diciembre de 2014).

Encuesta Mundial de Valores (2014): Encuesta Mundial de Valores, disponible en http://www. worldvaluessurvey.org/WVSOnline.jsp (consultado el 15 de marzo de 2015).

Encuesta Nacional de Seguridad Ciudadana (ENUSC) (2011): Encuesta Nacional de Seguridad Ciudadana 2011, Instituto Nacional de Estadísiticas, Santiago.

(ENUSC) (2012): Encuesta Nacional de Seguridad Ciudadana 2012, Instituto Nacional de Estadísiticas, Santiago.

(ENUSC) (2013): Encuesta Nacional de Seguridad Ciudadana 2013, Instituto Nacional de Estadísiticas, Santiago.

(ENUSC) (2014): Encuesta Nacional de Seguridad Ciudadana 2014, Instituto Nacional de Estadísiticas, Santiago.

Encuesta Nacional de Victimización y Percepción sobre Seguridad Pública (ENVIPE) (2012): Encuesta Nacional de Victimización y Percepción sobre Seguridad Pública 2012, Instituto Nacional de Estadística y Geografía, México D.F.

Encuesta Nacional de Victimización y Percepción sobre Seguridad Pública (ENVIPE) (2013): Encuesta Nacional de Victimización y Percepción sobre Seguridad Pública 2013, Instituto Nacional de Estadística y Geografía, México D.F.

Encuesta Nacional de Victimización y Percepción sobre Seguridad Pública (ENVIPE) (2014): Encuesta Nacional de Victimización y Percepción sobre Seguridad Pública 2014, Instituto Nacional de Estadística y Geografía, México D.F.

Encuesta Nacional sobre Cultura Política y Prácticas (ENCUP) (2008): Encuesta Nacional sobre Cultura Política y Prácticas Ciudadanas 2008, Secretaría de Gobierno, México D.F.

Encuesta Nacional sobre Cultura Política y Prácticas (ENCUP) (2012): Encuesta Nacional sobre Cultura Política y Prácticas Ciudadanas 2012, Secretaría de Gobierno, México D.F.

Esquivel, G. (2015): Desigualdad extrema en México. Concentración del poder político y económico en México, Oxfam, México D.F.

Fiscalía de Chile (2015): Resumen estadístico de los delitos de corrupción, disponible en http://www. fiscaliadechile.cl/Fiscalia/areas/cor-resumen.jsp

Garretón, M. (2003): Incomplete democracy, University of North Carolina Press, Chapel Hill. (2008): Política y sociedad en Chile. Una mirada desde el bicentenario, en M. Figueroa y M. Vicuña (coords.): El Chile del bicentenario, Universidad Diego Portales, Santiago.

(2010): Sentido, régimen y actores de la política. Cambios, continuidades y perspectivas, en R. Lagos (ed.): Cien años de luces y sombras, Tomo 1, Taurus, Santiago. 
(2011): Movilizaciones y movimiento social en la democratización política chilena, en R. Quirosa-Cheyrouze y Muñoz: La sociedad española en la transición, Siglo XXI, Madrid.

(2012): Igualdad: dimensiones, luchas y pactos sociales, en R. Casas y H. Carton de Grammont (comps.): Democracia, conocimiento y cultura, IIS, UNAM, México D.F.

(2013): Cultura y democratización en Chile. Los nuevos desafíos, Comunicación y Medios, 27.

Garretón, M. y G. Cumsille (2002): Las percepciones de la desigualdad en Chile, Revista Proposiciones, 34. Instituto Internacional para la Democracia y la Asistencia Electoral (IDEA) (2014): Estadísticas electorales, disponible en http://www.idea.int/uid/ (consultado el 10 de febrero de 2015).

Institute for Economics and Peace (2015a): Mexico Pace Index. Analyzing the changing dynamics of peace in Mexico, Institute for Economics and Peace.

(2015b): Global Pace Index. Measuring pace, its causes and its economic value, Institute for Economics and Peace.

(2015c): Pace and Corruption, Institute for Economics and Peace.

Instituto Mexicano de la Competitividad (IMCO) (2015): Índice de Competitividad Internacional. La corrupción en México: Transamos y no avanzamos, IMCO, México D.F.

Instituto Nacional de Estadísitica y Geografía (INEGI) (2013): Estadísticas sobre relaciones laborales, INEGI, México D.F.

Jiménez, M., I. Vivero y C. Báez (2003): México, en M. Alcántara y F. Friedenberg (coords.): Partidos políticos de América Latina, Centroamérica, México y República Dominicana, Fondo de Cultura Económica, IFE, México D.F.

Keane, J. (2002): “Miedo y democracia", Pasajes, 8.

Kessler, G. y D. Merklen (2013): Una introducción cruzando el Atlántico, en R. Castells, G. Kessler, D. Merklen y N. Murard: Individuación, Precariedad, Inseguridad: ¿desinstitucionalización del presente?, Paidós, Buenos Aires.

La Jornada (2015): Asegura Peña que la informalidad bajó tres puntos porcentuales, 24 de marzo.

La Tercera (2015): Así será el proceso para la creación de una nueva Constitución, 14 de octubre.

(2015): Bachelet promulgó ley que pone fin al binominal: Era un sistema concebido a partir del miedo, 27 de abril.

Latinobarómetro (2013): Informe 2013, Corporación Latinobarómetro, Santiago.

(2015): Informe 2015, Corporación Latinobarómetro, Santiago.

Lechner, N. (2002): Los desafíos políticos del cambio cultural, Revista Nueva Sociedad, Democracia y Política en América Latina, 184.

Maffesoli, M. (2004): El tiempo de tribus. El ocaso del individualismo en las sociedades posmodernas, Siglo XXI, México D.F.

Mayol, A., C. Azócar y C. Azócar (2013): El Chile profundo. Modelos culturales de la desigualdad y sus resistencias, Liberalia Ediciones, Santiago.

Orellana, P. (2007): Chile, un caso de corrupción oculta, Revista de Sociología, 21.

Organización para la Cooperación y el Desarrollo Económicos (OCDE) (2012): Key employment statistics, disponible en http://www.oecd.org/els/emp/howdoesyourcountrycompare-mexico.htm 
Piketty, T. (2014): El capital en el siglo XXI, Fondo de Cultura Económica, México D.F.

Ruiz, C. y G. Boccardo (2014): Los chilenos bajo el neoliberalismo. Clases y conflicto social, Nodo XXI/El Desconcierto, Santiago.

Sebesta, L. (2014): Raíces de la violencia: para una nueva genealogía de Hobbes a Marx, en

W. Ansaldi y V. Giordano (coords.): América Latina. Tiempos de violencias, Paidós, Buenos Aires.

Secretaría de Desarrollo Social (SEDESOL) (2004): Encuesta sobre Corresponsabilidad y Participación Ciudadana, SEDESOL, México D.F.

Sepúlveda, A. (1985): La formación del Estado nacional en Chile, Quinto Centenario, 7.

Stiglitz, J. (2012): El precio de la desigualdad. El 1\% de la población tiene lo que el 99\% necesita, Santillana Ediciones Generales, México D.F.

Tejera, H. (2009): Prácticas políticas, imaginarios y ciudadanía: las disonancias entre cultura y democracia en la ciudad de México, Revista Mexicana de Sociología, 71 (2).

Tilly, C. (2000): La desigualdad persistente, Manantial, Buenos Aires.

Transparencia Internacional (2015): Índice de Percepción de la Corrupción, 1995-2014, disponible en http://www.transparency.org/gcb2013/country/?

Vargas, D. y M. Merino (2012): El papel de los espacios públicos y sus efectos en la cohesión social: experiencia de política pública en México, Estudios Sociológicos, 30 (9). 